\title{
ELEMENTOS FUNDAMENTAIS DA ÉTICA DA LIBERTAÇÃO PARA A PRODUÇÃO DO BLOCO DE LUTAS DOS OPRIMIDOS
}

Guilherme Dornelas Camara ${ }^{1}$

\section{Resumo}

O objetivo desse ensaio é analisar os elementos fundamentais que a Ética da Libertação, proposta por Enrique Dussel, oferece para a produção do bloco de lutas dos Oprimidos. Baseada no princípio ético-material da produção e reprodução da vida humana em comunidade, essa ética destaca a relevância da Economia Política no processo de libertação. $\mathrm{O}$ ponto de partido na materialidade da vida humana oprimida caracteriza a corporalidade sofredora desde o imperativo de uma necessidade absoluta: ter que vender a sua força de trabalho para garantir a produção e reprodução de sua vida e de sua família. A partir daí são discutidos conceitos como valor, mais-valor, capital, utopia e libertação. Situados na contradição entre Totalidade e Exterioridade, esses conceitos contribuem para a produção do Consenso dos Oprimidos inaugurado pelo povo.

Palavras-chave: Ética da Libertação. Oprimidos. Totalidade. Exterioridade. Povo.

\section{FUNDAMENTAL ELEMENTS OF THE ETHICS OF LIBERATION FOR PRODUCING THE STRUGGLES OF THE OPPRESSED}

\begin{abstract}
The aim of this essay is to analyze the fundamental elements that the Ethics of Liberation, proposed by Argentinian philosopher Enrique Dussel, brings to the production of the struggles of the Oppressed. Based on the ethical-material principle of the production and reproduction of human life in community, this ethics highlights the relevance of Political Economy to the process of liberation. The standpoint in the materiality of

\footnotetext{
${ }^{1}$ Docente e pesquisador da Escola de Administração - UFRGS. E.mail: guilherme.dornelas@ufrgs.br. Revista Brasileira de Estudos Organizacionais • v. 3. n. 1, p. 18-41, jun.2016, eISSN: 2447-4851 Doi 10.21583/2447-4851.rbeo.2016.v3n1.66 Sociedade Brasileira de Estudos Organizacionais
} 
oppressed human life characterizes the corporality as suffering due to the imperative of an absolut necessity: it must sell its laborforce to guarantee the production and reproduction of its own and its family's lives. From there, concepts such as value, surplus value, capital, utopy and liberation are discussed. Stated in the contradiction between Totality and Exteriority, these concepts help to produce the Consensus of the Oppressed inaugurated by the people.

Keywords: Ethics of liberation. Oppressed. Totality. Exteriority. People

\section{ELEMENTOS FUNDAMENTALES DE LA ÉTICA DE LA LIBERACIÓN PARA LA PRODUCCIÓN DEL BLOQUE DE LUCHAS DE LOS OPRIMIDOS}

\section{Resumen}

El objectivo deste ensaio es analisar los elementos fundamentales que la Ética de la Liberación, propuesta por Enrique Dussel, ofrece para la producción del bloque de luchas de los Oprimidos. Basada en el princípio etico-material de la producción y reproducción de la vida humana en comunidad, esta ética destaca la relevancia de la Economía Politica para el proceso de liberación. El punto de partida em la materialidad de la vida humana oprimida caracteriza la corporeidad que sufre desde el imperativo de una necesidad absoluta: deber vender su fuerza de trabajo para garantizar la producción y reproducción de su vida y de su família. Desde ahí se ponen en discusión conceptos como valor, plusvalor, capital, utopía y liberación. Hubicados en esta contradicción entre la Totalidad y la Exterioridad, estes conceptos contribuyen para la producción del Consenso de los Oprimidos abierto por el pueblo.

Palabras-clave: Ética de la Liberación. Oprimidos. Totalidad. Exterioridad. Pueblo. 


\section{ELEMENTOS FUNDAMENTAIS DA ÉTICA DA LIBERTAÇÃO PARA A PRODUÇÃO DO BLOCO DE LUTAS DOS OPRIMIDOS \\ Guilherme Dornelas Camara}

\section{Introdução}

O objetivo desse ensaio é analisar os elementos fundamentais que a Ética da Libertação, proposta por Enrique Dussel2 ${ }^{2}$, oferece para a produção do Consenso dos Oprimidos. A Ética da Libertação inicia com a afirmação de que "esta é uma ética da vida. A negação da vida humana é agora nosso tema. O ponto de partida forte e decisivo de toda a crítica [...] é a relação que se produz entre a negação da corporalidade, expressa no sofrimento das vítimas, dos dominados, e a tomada de consciência desta negatividade" (DUSSEL, 2002, p. 313). Essa é, portanto, uma ética material.

É necessário destacar, de pronto, que essa proposição não parte de uma afirmação idealista da Ética como fundamento da ação humana. Não se trata da defesa de uma posição teleológica ${ }^{3}$ da Ética, isto é, da assertiva de um imperativo categórico apriorístico que orienta o julgamento do 'fim' de uma ação, como proposto, por exemplo, por Kant (2005). Tampouco se trata da defesa de uma deontologia ${ }^{4}$, da elaboração de uma teoria moral que guia e avalia as escolhas sobre o que deve ser feito e como as pessoas devem agir, a partir do que foi estabelecido como o ' certo' (ALEXANDER e MOORE, 2012).

A diferença essencial que a Ética da Libertação apresenta em relação a essas teorias morais que vislumbram a totalidade das ações humanas encontra-se no princípio ético-material da produção e reprodução da vida humana associada (DUSSEL, 2002). Esse princípio não expressa apenas um 'direito à vida', mas coloca a 'vida' como única possibilidade de ser do humano. Assim, todas as ações, processos, estruturas e sistemas que atentem contra a 'vida humana' são seu

2 Enrique Dussel é filósofo, nascido em 1934, na cidade de La Paz, na província de Mendoza, doutor em Filosofia pela Universidad Complutense de Madrid e em História pela Sorbonne. Se mudou para o México em 1975 como exilado político. Atualmente, é professor no Departamento de Filosofia no campus de Iztapalapa da Universidad Autónoma Metropolitana (UAM) e Reitor da Universidad Autónoma de la Ciudad de México (UACM).

3 De acordo com Ferrater Mora (2007, p. 346), o termo 'teleologia' foi empregado a partir do século XVIII para expressar o modo de explicação que se baseia nas causas finais. "Apelamos à causa final, ou teleológica quando ante a uma entidade ou processo perguntamos 'para quê?'."

4 Para Alexander e Moore (2012) as teorias deontológicas estabelecem que as normas devem ser obedecidas por todos os agentes morais porque delas deriva o que é o Certo. Se uma ação não está de acordo com o que é o Certo, ela não deve ser realizada, independente do Bem que possa causar. 
contraditório. Tomando como fundamento a própria 'vida humana' não cabe qualquer justificativa de atentado contra ela, em curto, médio ou longo prazo, mesmo que dentro do sistema moral vigente ela seja 'correta', 'válida' ou 'necessária'. Esse princípio volta-se para as condições de 'produção e reprodução' da vida em sua própria materialidade, isto é, na realidade do trabalho enquanto atividade vital do trabalhador (MARX, 1980). A contradição entre trabalho e capital, portanto, é determinante para a proposição desta Ética.

Devido a isso, cabe destacar a importância que a Economia Política possui na arquitetônica da Ética da Libertação. Não significa que a Ética está submetida à Economia; não é a posição de algumas leituras reducionistas de matiz estruturalista que traduz a Economia uma superestrutura que determina todas as outras dimensões estruturais, como a Política, o Social, a Ética e os processos simbólicos subjetivos. Trata-se de uma elaboração da realidade material como concreto, isto é, como a unidade do diverso que não é apenas a síntese, o resultado a que a reflexão chega, mas também o seu ponto de partida da investigação que se empreende. A explicação filosófica é dada por Marx (2007, p. 21), ele mesmo:

O concreto é concreto porque é a síntese de múltiplas determinações, portanto, unidade do diverso. Aparece no pensamento como processo de síntese, como resultado, não como ponto de partida, ainda que seja o verdadeiro ponto de partida e, em consequência, o ponto de partida também da intuição e da representação. No primeiro caminho, a representação plena é volatilizada em uma determinação abstrata; no segundo, as determinações abstratas conduzem à reprodução do concreto pelo caminho do pensamento. Aqui está porque Hegel caiu na ilusão de conceber o real como resultado do pensamento, que partindo de si mesmo, se concentra em si mesmo, aprofunda-se em si mesmo e se move por si mesmo, enquanto o método que consiste em elevar-se do abstrato ao concreto é para o pensamento só uma maneira de apropriar-se do concreto, de reproduzí-lo como um concreto espiritual. Mas isso não é de forma alguma o processo de formação do próprio concreto. 


\section{ELEMENTOS FUNDAMENTAIS DA ÉTICA DA LIBERTAÇÃO PARA A PRODUÇÃO DO BLOCO DE LUTAS DOS OPRIMIDOS \\ Guilherme Dornelas Camara}

A relevância da Economia Política na Ética da Libertação se localiza justamente pelo seu ponto de partido na materialidade da vida humana oprimida. Esse ponto de partida caracteriza a corporalidade sofredora desde o imperativo de uma necessidade absoluta: ter que vender a sua força de trabalho para garantir a produção e reprodução de sua vida e de sua família. Isso não é o caso exclusivo de um trabalhador hipotético, mas de todo o povo que não é proprietário dos meios de produção. Por isso, é mister compreender as dinâmicas que determinam a vida desse povo produtor como um povo trabalhador; povo que, ao produzir sua vida, no sistema do capital, contraditoriamente, a desgasta.

Então, no final da década de 1970, quando estava no exílio no México, Dussel começou a se aprofundar em Marx, pois a crescente miséria do continente latino-americano lhe fazia constatar que a filosofia latino-americana precisaria construir uma econômica e uma política firmes, para só depois apoiar também a parte pragmática (DUSSEL, 1995). Era necessário, portanto, levar a termo uma crítica do capitalismo como sistema que impede a realização do princípio ético-material crítico da produção e reprodução da vida.

Dussel (2012, p. 12) empreendeu um estudo minucioso da produção teórica de Marx, em que se destaca o seu Comentário aos Grundrisse - aos "Elementos Fundamentais para a Crítica da Economia Política", que Marx escreveu entre 1857 e 1858 . Para Dussel, os Grundrisse são "histórica, biográfica e teoricamente o início do pensamento crítico de Marx". Neles, segundo Dussel (2012, p. 13, grifos do autor) "Marx descobre pela primeira vez explicitamente a 'essência' do seu pensar teórico: a questão do valor como fundamento do conceito de mais-valor".

Para a elaboração desse ensaio, empreendi uma releitura dos Grundrisse e dos Comentários de Dussel, três anos após o primeiro contato com as obras, em 2010. Naquela ocasião, havia estipulado três objetivos bastante pretensiosos: identificar as referências a Marx no arcabouço conceitual de Enrique Dussel; identificar as contribuições que a produção teórica de Marx trazem para a análise que Dussel faz da realidade social da América Latina; e compreender a análise marxista que Enrique Dussel faz dessa realidade social. Cabe dizer que aquele foi um primeiro exercício de compreender o marxismo de Dussel, pois minhas leituras do autor, até então, focavam nas contribuições que sua obra fazia para uma apropriação 
crítica da Filosofia da Alteridade de Emmanuel Lévinas para o contexto latino-americano.

Neste ensaio, meu objetivo é mais focado, porém exige uma elaboração maior das ideias. Objetivo analisar os elementos fundamentais que a Ética da Libertação oferece para a produção do Consenso dos Oprimidos, produzido a partir da conscientização (FREIRE, 1970) de que “o Outro oprimido e excluído não é uma realidade formal vazia: é um mundo pleno de sentido, uma memória, uma cultura, uma comunidade, o 'nós-estamos-sendo' como realidade 'resistente'"' (DUSSEL, 2004, p. 282).

Com isso, Dussel atribui um conteúdo material à categoria 'interpelação' proposta por Emmanuel Lévinas (2000; 2005), especialmente "nesta época da história, no final do século XX e começo do III milênio, especialmente para as vítimas excluídas do atual processo de globalização do capitalismo mundial" (DUSSEL, 2002, p. 572, grifos do autor). Para o autor, vivemos 'a negação da vida' em concreto; o consenso dos Oprimidos divulga a possibilidade de uma "plena 'comunidade (de produção, distribuição, troca, consumo) de vida' sem dominação e sem trabalho: é o 'reino da liberdade', mas além de todo modo de produção possível".

A ideia de consenso, aqui, não deve ser compreendida como um consenso entre classes, como a formação de uma aliança entre capital e trabalho ou ainda como a formação de um bloco de vanguarda histórica que se propõe contraditório ao status quo. O Consenso dos Oprimidos é a formação de um bloco de lutas dos Oprimidos, aqui categoria filosófica, em que as diferentes lutas de negação e desafio às diferentes frentes de opressão se articulam, fortalecendo o povo trabalhador, mirando para a superação do sistema de opressão do capital.

Desde o particular do sistema capitalista e da sua relação de negação da alteridade de suas vítimas, de seus excluídos, de seus pobres, Dussel elabora uma Ética que se abre para o devir de uma sociedade onde se instaura um novo bom. Nessa sociedade, a relação social de exploração de um homem sobre o outro é eticamente perversa, pois não toma as pessoas (os trabalhadores) como um fim em si mesmo, mas como uma mediação para a geração de valor para os capitalistas.

Por isso, é importante compreender o desenvolvimento da Teoria do Valor, elaborada por Marx nos Grundrisse, onde ele desenvolve uma "ontologia do capitalismo a partir de uma metafísica da vida, da sensibilidade humana como necessidade, da pessoa do trabalhador como exterioridade" (DUSSEL, 2012, p. 20). Partindo dessa ontologia, almejo 
identificar as determinações reais do capitalismo, tarefa essencial para o processo de conscientização necessário ao Consenso dos Oprimidos.

Para tanto, o método de estudo seguiu as recomendações de Dussel: avançando nos Grundrisse ao mesmo tempo em que acompanhava os Comentários do filósofo argentino, em uma jornada lado a lado com Marx e Dussel. De modo a realizar a tarefa proposta, organizo esse texto da seguinte maneira: na próxima seção, discuto os elementos da Economia Política de Marx elementares para a Ética da Libertação; na seção seguinte, elaboro alguns conceitos que permitem compreender o sistema de exploração capitalista como totalidade e o consenso dos oprimidos como exterioridade. Ao final, teço breve comentários.

\section{A Economia Política da Ética da Libertação}

De acordo com Dussel (2012, p. 30), a análise da produção é o momento fundamental e primeiro do materialismo de Marx, e por ele o autor estabelece uma clara diferenciação entre o momento ou instância tecnológico-produtiva e o momento ou a instância econômica. Nos Grundrisse, Marx (2007, p. 3) inicia sua análise tomando como objeto a considerar "em primeiro termo, a produção material. Indivíduos que produzem em sociedade, ou seja, a produção dos indivíduos socialmente determinada: esse é naturalmente o ponto de partida". Com isso, Marx rejeita a figura típica do caçador ou pescador só e isolado, “[...] com quem Smith e Ricardo começam, pertencem às imagens desprovidas de fantasia que [...] de modo algum expressam uma simples reação contra um excesso de refinamento e um retorno a uma mal-entendida vida natural".

Isso se justifica, pois, produção realizada por um indivíduo isolado, fora do âmbito da sociedade é um grande absurdo. Era dessa maneira absurda que economistas clássicos como Adam Smith e Ricardo iniciavam a sua análise da produção e do produtor. Para Marx (2007, p. 5), a produção é a produção de indivíduos que vivem em sociedade

quanto mais longe remontamos na história, tanto mais o indivíduo - e por consequente o indivíduo produtor aparece como dependente e formando parte de um todo maior: em primeiro lugar e de uma maneira ainda muito inteiramente natural, da família e dessa família ampliada que é a tribo; mais tarde, das comunidades em suas formas distintas, resultado do antagonismo e da fusão das tribos. Somente ao chegarmos ao século XVIII, com a 'sociedade civil', as diferentes formas de conexão social aparecem ante o indivíduo como um simples meio para 


\section{ELEMENTOS FUNDAMENTAIS DA ÉTICA DA LIBERTAÇÃO PARA A PRODUÇÃO DO BLOCO DE LUTAS DOS OPRIMIDOS \\ Guilherme Dornelas Camara}

alcançar os seus fins privados, como uma necessidade exterior. [...] O homem é, no sentido mais literal, um

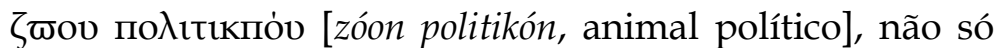
um animal social, mas um animal que só pode individualizar-se na sociedade. (MARX, 2007, p. 4)

Portanto, para ele, falar de produção implica "ou descrever o processo de desenvolvimento histórico nas suas diferentes fases; ou então declarar de inicio que nos referimos a uma determinada época histórica bem definida, como por exemplo à produção burguesa moderna, que é na realidade o nosso tema específico ". Essa definição do homem como animal político que trabalha para produzir sua vida e só existe em sociedade é fundamental para a Ética da Libertação, pois permitirá a Dussel (2012) encontrar na relação social de trabalho a origem do princípio de negação da vida dos oprimidos.

O ponto de partida de Marx (2007, p. 6) nos Grundrisse está na produção, mas não na produção 'em geral' e nem na 'produção geral', "pois toda produção é sempre um ramo particular da produção, existente a partir de seus determinantes históricos, ou ainda, a produção em geral de uma sociedade em uma época dada". Cabe, nessa passagem, destacar uma das principais reflexões teóricas de Marx, que vai diferenciá-lo dos economistas políticos clássicos e, também, dos materialistas vulgares. Não se trata da afirmação de que a realidade é material porque o material é a realidade, como uma tautologia, mas de situar seu edifício teórico no seio do sistema do capital. A discussão da precedência do material ao ideal não se dá, aqui, em termos de uma filosofia pura, mas em termo de que em uma sociedade em que a produção é o determinante da vida dos sujeitos é pela análise das condições objetivas dessa produção que é possível apreender todo o sistema e como vivem as pessoas.

Tratar da produção como produção material, permitiu a Marx compreender as correlações e codeterminações entre produção, distribuição, troca e consumo. Para Marx, as determinações são momento constitutivo essencial da coisa; nesse caso, da produção. São determinações essenciais aquelas que são comuns a todas as coisas que dizem ser as mesmas. No caso da produção, as determinações essenciais são: um sujeito que produz, um objeto trabalhado, um instrumento com que ele trabalha e um trabalho passado (DUSSEL, 2012).
a) Produção e Consumo 


\section{ELEMENTOS FUNDAMENTAIS DA ÉTICA DA LIBERTAÇÃO PARA A PRODUÇÃO DO BLOCO DE LUTAS DOS OPRIMIDOS \\ Guilherme Dornelas Camara}

A frase com que Marx (2007, p. 32) inicia a reflexão sobre produção e consumo dá o tom da oposição de seu pensamento à economia tradicional da época, ao passo que evidencia a codeterminação entre essas rubricas: "a produção é também imediatamente consumo. Duplo consumo, subjetivo e objetivo: o indivíduo que, ao produzir, está desenvolvendo as suas capacidades, está também dispensando-as, isto é, consome-as no ato da produção". Isso dá a dimensão das relações reais entre produção e consumo, no sentido de que tanto a produção determina o consumo, quanto o consumo cria necessidades de produção, em outras palavras, "Marx sabia bem que a matéria, abstratamente primeira, era concretamente determinada com anterioridade -neste caso- pelo tendencial: a necessidade do objeto funda a possibilidade de sua produção. Define a produção como objetivação, e o consumo como subjetivação (DUSSEL, 2012, p. 42).

Marx (2007) afirma que essa relação entre a produção e o consumo, ou seja, entre a própria objetivação e a subjetivação no processo de produção e reprodução da vida não é a apropriação imediata do produto por aquele que o consome. Na realidade social, a distribuição interpõe-se entre o produtor e os produtos, mediante leis sociais. Sem o consumo, o ser humano não pode produzir. Como produção é realização, sem o consumo o homem não pode realizar. Por um lado, o consumo que permite ao homem apenas a sobrevivência, é um consumo que permite ao homem uma produção que não chega a realização. Por outro lado, o consumo dos produtos, convertido em razão-de-ser na sociedade inviabiliza a realização do ser humano, posto que toda a produção será pautada pelo consumo e o consumo ditará a produção.

b) Produção e Distribuição

De acordo com Dussel (2012), é habitual, na economia capitalista, privilegiar-se a determinação da produção sobre a distribuição, pois a organização da distribuição dos produtos está determinada pela organização da produção. Nesse sentido, Marx afirma que a distribuição é ela mesma um produto da produção. No entanto, o olhar dialético apresenta a questão em um outro ângulo, qual seja: a produção também é determinada pela distribuição, "posto que a produção parte necessariamente de uma dada distribuição de meios de produção, pelo menos a distribuição assim entendida precede a produção e constitui a sua condição prévia [...]. Assim a distribuição determina a produção" (MARX, 2007, p. 26-7) 


\section{ELEMENTOS FUNDAMENTAIS DA ÉTICA DA LIBERTAÇÃO PARA A PRODUÇÃO DO BLOCO DE LUTAS DOS OPRIMIDOS \\ Guilherme Dornelas Camara}

Nesse aspecto, o trabalho assalariado está evidentemente vinculado à produção, pois quem não detem capital nem propriedade agrária é condenado, por essa distribuição social, ao trabalho assalariado. Analisando esse tópico, Dussel (2012, p. 44) esclarece que "a produção determina materialmente a distribuição de objetos, mas a distribuição determina praticamente (política ou eticamente) a produção nos seus agentes. Isso significa que o nível prático-político não pode ser descartado como um nível supraestrutural determinado pela base material. Muito pelo contrário, o nível político determina, por sua vez, a materialidade fundada da produção". Ou seja, a determinação das relações de produção é um ato próprio prático (e não material) da distribuição.

Com isso, a relação entre distribuição e produção se aproximada daquela entre produção e consumo, pois a distribuição é determinada pela estrutura da produção de tal modo que aquele que produz de forma assalariada participa na repartição dos produtos apenas sob a fórma de salário. O consumo de que é capaz não é o consumo daquilo que produziu, mas o consumo do salário, contrapartida da venda da sua força de trabalho. Ou seja, a distribuição determina o consumo assim como o consumo é determinante da distribuição.

c) Produção e Troca

Para Marx (2007, p. 53), "não existe troca sem divisão do trabalho. A troca privada pressupõe a produção privada." No entanto, a produção também é determinada pela troca, pois é neste momento que a fórmula básica do capital D-M-D' se realiza; “quando o mercado - ou seja, a esfera da troca - se estende, a produção amplia seu âmbito e se subdivide mais profundamente (MARX, 2007, p. 53).

A troca não é mais do que um momento mediador entre, por um lado, a produção e a distribuição que aquela determina e, por outro lado, o consumo. Dado que o próprio consumo aparece também como um momento da produção - é evidente que a troca se inclui na produção, e é também um seu momento. Dando continuidade à análise que Dussel faz das relações entre esses momentos, é óbvio afirmar que a produção determina materialmente a troca. No entanto, qual a determinação que a troca tem na produção? Ao mudar a direção da relação, essa determinação não é apenas material, mas é prática. No entanto, diferente do que ocorre 
com a distribuição, essa prática é mais econômica do que política, pois a troca é mediação entre a produção e a distribuição.

A análise da produção elaborada por Marx, e aqui comentada por Dussel, permite reconhecer que a produção, a distribuição, a troca e o consumo constituem elementos de um todo, e cada um deles representa diversidade no seio da unidade (MARX, 2007). Contudo, visto que se determina contraditoriamente a si própria, a produção predomina não apenas sobre o setor produtivo, mas também sobre os demais elementos; é a partir dela que o processo sempre se reinicia. Pensar na transformação da troca, da distribuição e/ou do consumo para modos mais justos do que os atuais obriga, portanto a conceber a alteração do próprio modo de produção como condição sine qua non.

Nesse sentido, o princípio ético-material que funda a Ética da Libertação se apresenta perante o sistema vigente e a sua organização da produção como uma exterioridade, como uma interpelação para que se cumpra a obrigação ética da vida: "a reprodução e o desenvolvimento da vida humana" (DUSSEL, 2002, p. 339). Apesar da generalidade que é proposta por esse princípio, ele não está colocado a priori à ação humana, mas apenas se realiza enquanto ação humana no contexto das relações de produção vigentes.

Nos Grundrisse, Marx (2007, p. 23) indica que as categorias "exprimem formas e modos de existência, amiudadamente simples aspectos desta sociedade, deste sujeito". O sujeito de que Marx nos fala é a socidade capitalista moderna, cujas categorias são fundamentais para exprimir "as relações desta sociedade, e que permitem compreender a sua estrutura". As categorias tem uma importância dupla, pois "permitemnos, ao mesmo tempo, entender a estrutura e as relações de produção das sociedades desaparecidas, sobre cujas ruínas e elementos ela se ergueu, cujos vestígios ainda não superados continua a arrastar consigo, ao mesmo tempo que desenvolve em si a significação plena de alguns indícios prévios, etc."

Uma melhor compreensão da questão da ordem das categorias, seguindo Marx (2007), deve passar pelo reconhecimento de que, no método dialético, a ordem do pensar teórico (que surge da realidade, mas não se confunde com a realidade) deve estar determinada pela sua posição sincrônica e essencial na sociedade capitalista moderna, que, para Marx (2007, p. 24) é sujeito "dado tanto na realidade como na mente". Fica um indício desde essa colocação de Marx: as categorias não são ideias puras que surgem das ideias, mas também não são a realidade ela própria em 
sua totalidade. As categorias exprimem as abstrações feitas da totalidade da realidade em análise. As determinações abstratas elaboradas no método dialético são categorias que permitem mediar interpretativamente o real.

Para Dussel (2012, p. 57), “a ordem que guardam entre si as categorias é a mesma ordem que guardam as determinações como momento da realidade da sociedade burguesa concreta. [...] Ao compreender a realidade da sociedade burguesa, compreendo ao mesmo tempo a realidade das sociedades anteriores menos complexas". Portanto, seria e errado apresentar a sucessão das categorias econômicas pela ordem que foram historicamente determinantes, já que isso não permitiria a compreensão exata da sociedade burguesa e, desde ela, da organização das sociedades que a precederam. Seguindo nesse ordenamento, posso proceder à categoria 'dinheiro', como elaborada por Marx (2007).

Para adentrar na análise do dinheiro, Marx (2007, p. 83) parte do conhecimento que os economistas tradicionais apresentavam sobre o tema. "Os economistas expressam a necessidade permanente da troca e do valor-de-troca como mediador geral da seguinte maneira: cada um persegue o seu interesse privado e só o seu interesse privado, e desse modo, sem saber, serve ao interesse privado de todos, ao interesse geral". A lógica consequencialista que subjaz essa afirmação é atacada por Marx de modo contundente:

A dependência mutua e generalizada dos indivíduos reciprocamente indiferentes constitui o seu nexo social. Este nexo social se expressa no valor de troca, e só nesse nele a atividade própria ou o produto se transformam para cada indivíduo em uma atividade ou em um produto para ele mesmo. $\mathrm{O}$ indivíduo deve produzir um produto universal: o valor de troca, ou considerado este em si isoladamente e individualizado, dinheiro. Por outro lado, o poder que cada indivíduo exerce sobre a atividade dos outros ou sobre as riquezas sociais, o possui enquanto é proprietário de valores de troca, de dinheiro. Seu poder social, assim como seu nexo com a sociedade, ele leva consigo no bolso (MARX, 2007, p. 84).

Aqui ganha especial destaque o dinheiro, como o nexo social dos indivíduos. As trocas são realizadas para que se obtenha mais dinheiro. $\mathrm{O}$ salário é pago na forma de dinheiro e é por meio deste que o trabalhador adquire os valores-de-uso necessários à reprodução da sua existência. $\mathrm{O}$ valor-de-troca é "algo universal no qual toda individualidade, todo caráter próprio é negado e cancelado" (DUSSEL, 2012, p. 121). "O capital vem 
inicialmente da circulação e, sobretudo, seu ponto de partida é o dinheiro. O dinheiro que entra em circulação e, ao mesmo tempo, retorna de si para si mesmo é a última exigência na qual o dinheiro se suspende. Isso é, ao mesmo tempo, o primeiro conceito de capital, e a primeira forma em que ele aparece" (MARX, 2007, p. 86).

Nessa passagem, Marx nos apresenta a maneira pela qual ocorre a superação do capital em relação ao dinheiro, posto que o dinheiro se torna o conceito e a forma do capital, ou seja, sem o dinheiro não há capital, assim como sem o momento de circulação do dinheiro não há a produção capitalista, pois os produtos apenas são manufaturados devido o valor-detroca que encerram, devido a sua futura existência como mercadoria a ser trocada por dinheiro.

De acordo com Dussel (2012, p. 121), “o dinheiro como capital é algo novo, distinto, diferente da sua existência como dinheiro". O que fica evidente na conceptualização do capital é o modo como o dinheiro é subsumido ao capital, ou seja, há uma passagem de um estágio inferior do dinheiro - meio de efetuar as trocas - para um estágio superior - dinheiro acumulado através das trocas. Nessa mudança de estágio o dinheiro passa a ser o objetivo ele mesmo, ou, nas palavras de Marx (2007, p. 87, grifos do autor):

O dinheiro se nega como algo que meramente se dissolve na circulação; mas ele também negou-se como algo que toma uma atitude dependente em relação à circulação. Essa negação, como um todo, em seu aspecto positivo, contém o primeiro elemento do capital. O dinheiro é a primeira forma na qual o capital aparece; dinheiro que é trocado por mercadoria e mercadoria que é trocada por dinheiro; esse movimento de comprar para vender, o qual produz o aspecto formal do comércio, do capital como capital mercantil, é encontrado nas condições priscas do desenvolvimento econômico; é o primeiro movimento no qual o valor-de-troca como tal forma o conteúdo não é só a forma mas também o seu próprio conteúdo.

Há que se fazer uma diferenciação aqui entre o dinheiro como capital e o capital como dinheiro. O dinheiro como capital indica uma determinação do dinheiro; que o dinheiro também é capital. O capital como dinheiro é uma das múltiplas determinantes do que é o capital como 
uma totalidade concreta, ou, uma unidade de múltiplas determinações (MARX, 2007). Ter a clareza dessa diferenciação permite reconhecer que o capital comercial é apenas uma forma de capital (a sua primeira forma). O dinheiro aparece, a partir de então, como componente do capital.

Em oposição a Adam Smith5, Marx afirma que o capital é uma soma de valores utilizados na produção de valores; o que seja: o capital é valor-de-troca se auto-reproduzindo. Aqui fica evidente o modo pelo qual o valor-de-troca é o ponto de partida. Se afirmo que o capital é valor-detroca que produz lucro, ou que tem a intenção de produzi-lo, então, o capital já está pressuposto na explicação, já que o lucro é uma relação específica do capital. Por isso, Marx (2007) sentencia que "o capital não é uma simples relação, mas um processo, em cujos vários momentos é sempre capital".

A realização do capital enquanto um processo tem ponto fundamental no valor, especificamente no valor-de-troca, posto que é apenas no capital que o valor-de-troca existe de tal modo que se preserva na circulação. Marx identifica nesse processo um curso auto-renovador da troca, no qual "o dinheiro e a mercadoria são sempre remanescentes", ou seja, no capital, o valor preserva a sua identidade em cada uma de suas diferentes substâncias. Enquanto essência do capital, o valor atravessa as substâncias do processo de modo a manter-se vivo, produzindo e reproduzindo o capital. O curso do capital acaba por obscurecer a essência última do capital, que é o valor. “O valor não é uma forma ou maneira de aparição do capital; é o capital mesmo em sua invisibilidade profunda, fundamental, essencial. As formas de 'aparição' do capital podem ser o dinheiro, a mercadoria, o produto etc. como capital. Mas o valor nunca pode aparecer na circulação como tal"' (DUSSEL, 2012, p. 127).

Se o capital comercial já é, em si, capital, ele constitui uma etapa prévia e determinante do capital industrial. Ao discorrer sobre essa transição, Marx (2007, p. 89) remete claramente à América Latina, quando afirma que o movimento de troca entre produtos e dinheiro é encontrado nas condições mais priscas do desenvolvimento econômico, "no interior de populações e entre populações para as quais o valor-de-troca não se

5 Para Smith, o capital é trabalho acumulado (realizado), propriamente, trabalho objetificado, que serve como meio para um novo trabalho (produção). Isso, considera Marx, permite apenas identificar o material do capital, sem evidenciar o seu caráter de relação. 
tornou, de modo algum, pressuposto da produção". A América Latina passa a existir, para a Europa, no capitalismo e, segundo Dussel (2012), é um dos fatores essenciais do nascimento do capitalismo.

No momento presente da América Latina enquanto Periferia do sistema-mundo capitalista, o projeto de transformação das pessoas em indivíduos solitários se realiza reforçando o dinheiro como mediador universal das relações sociais. Como afirma Dussel (2012, p. 88), “os indivíduos solitários só se comunicam na medida em que cada um produz uma mercadoria para o mercado e a troca por outra mercadoria que outrem produziu para o mesmo mercado. E a fundamental 'relação social' dos produtores se realiza somente na circulação". Assim, o que é social ganha um caráter perverso, pois não há um 'frente a frente' entre os trabalhadores, mas uma relação coisificada no mercado, entre as coisas. " $\mathrm{O}$ dinheiro é uma mediação necessária para socializar as relações humanas em si mesmas, estas relações não existem, são abstratas. Os homens só se relacionam no 'mundo' das mercadorias, no mercado e fora dele são totalidades solipsistas. Esta é a crítica fundamental de Marx contra o capitalismo e contra sua pretensa 'liberdade individual' - que, na realidade, é alienação individualista" (DUSSEL, 2012, p. 88).

Nesse conjunto de relações mediadas pelo dinheiro, o capital se reproduz nas trocas entre os detentores dos meios de produção e dos trabalhadores que possuem apenas a sua força-de-trabalho como bem a ser vendido. Aí há, de um lado, a produção de riqueza e, de outro lado, a produção de pobreza. "O fato de reduzir o tempo necessário [o valor] significa baixar o salário enquanto valor-de-troca, ou seja, baixar o poder aquisitivo do trabalhador como comprador" (DUSSEL, 2012, p. 193) O desenvolvimento das forças produtivas permite que o trabalho necessário para remunerar o trabalhador seja exercido em menos tempo, o que aumenta o mais-valor do trabalho. A compreensão desse tema é fundamental entender o processo de empobrecimento da população.

Marx (2007, p. 321) traz, nesse contexto, a ideia de reserva de trabalhadores, pois "o capital só pode guardar o limite natural construído pela jornada de trabalho se põe junto a ela, simultaneamente, outra. Por isso, o capital promove o aumento de população, que é uma força natural não-paga do trabalho". Ao comentar sobre essa ideia da sobrepopulação, Dussel indica a sua contraditoriedade, pois enquanto o aumento da maisvalia tende a diminuir o tempo de trabalho necessário para o trabalhador, a população aumenta, levando a salários menores e maior mais-valia. A ideia da sobrepopulação, por isso, não pode ser desvinculada nem da mais-valia, nem do empobrecimento do trabalhador.

Ao encontro disso, Marx (2007, p. 323, grifos do autor) refere que 


\section{ELEMENTOS FUNDAMENTAIS DA ÉTICA DA LIBERTAÇÃO PARA A PRODUÇÃO DO BLOCO DE LUTAS DOS OPRIMIDOS \\ Guilherme Dornelas Camara}

já está contido no conceito de trabalhador livre que ele é pobre. De acordo com as suas condições econômicas, ele é apenas uma capacidade de trabalho vivo, então equipado com o que é necessário para viver. Necessidade de todos os lados, sem as objetividades necessárias para realizar-se como capacidade de trabalho. Se o capitalista não tem uso para a sua maisvalia de trabalho, então o trabalhador não pode exercer o trabalho que necessita; não produz o seu necessário. Então, ele não pode obtê-los através da troca; e mais, se ele os obtém, é apenas porque lhe são dadas esmolas. Ele pode viver como trabalhador apenas enquanto ele troca sua capacidade de trabalho por aquelas partes do capital que financiam o trabalho. Essa troca está amarrada às condições que são acidentais para ele, e indiferente para a sua presença orgânica. Ele é, portanto, um pobre virtual. Desde que é condição do capital que ele produza ainda mais mais-valor de trabalho, acaba que mais trabalho necessário fica sem emprego.

Nesse trecho fica evidente "a pobreza não como carência, mas como exclusão plena da riqueza objetiva" (MARX, 2007, p. 236), tanto pela diminuição do tempo necessário para a produção quanto pela exclusão do processo de trabalho de uma sobrepopulação.

Acima, ficou situado o nascimento da América Latina no surgimento do capital, sendo um de seus determinantes o capital. Está evidenciada, também, a relação entre sobrepopulação, mais-valor e pobreza. Com isso, acredito ter conjugado os elementos mais fundamentais para a compreensão da apropriação que Dussel faz dos Grundrisse para a Ética da Libertação, o que me leva à próxima seção.

\section{O Sistema de Exploração Capitalista como Totalidade e a Produção do Bloco de Lutas dos Oprimidos como Exterioridade}

Para Marx, a Totalidade é uma categoria que abrange o nível concreto do sistema capitalista real e seu nível espiritual - como a Totalidade do conhecimento científico burguês que legitima e naturaliza o 
capital). A categoria de Totalidade possibilita diferenciar o capital e o capitalismo, pois esse último é a Totalidade do modo de produção capitalista em múltiplas determinações. “O capital é o momento ontológico do sistema histórico do capitalismo, é a essência última que funda as categorias presentes nesse sistema, ao mesmo tempo em que é fundado pelas suas determinações" (DUSSEL, 2012, p. 339).

Partindo da ideia de Totalidade, nesse sistema, o dinheiro não é apenas dinheiro, mas existe como dinheiro como capital, e o próprio trabalho, que é o contraditório histórico da essência desse sistema, é transformado em trabalho como capital. A Totalidade encerra a forma e o conteúdo do sistema do capital, como fica evidente quando Marx (2007, p.377, grifos do autor) afirma que "esse movimento de comprar para vender, o qual produz o aspecto formal do comércio, do capital como capital mercantil, é encontrado nas condições priscas do desenvolvimento econômico; é o primeiro movimento no qual o valor-de-troca como tal forma o conteúdo - não é só a forma mas também o seu próprio conteúdo".

No entanto, não seria correto conceber o capital apenas como os seus determinantes. Isso não atingiria a categoria de totalidade. Não se deve confundir capital com a circulação, com o valor, com o dinheiro ou com o mais-valor. Para Dussel (2012, p. 347), o capital "é a totalidade de todas essas determinações, é o o sujeito (a substância) de todas elas; é a unidade dos diversos processos, o movimento e permanência como capital circulante e criador de valor como capital produtivo".

A ideia de Totalidade não deve, contudo, ser compreendida como o apogeu do sistema, mas entendido como processo que está em expansão contínua, em direção a engolfar todos os espaços, as vidas e os processos subjetivos como espaços, vidas e subjetividade capitalista. Submetido ao imperativo da troca de sua força vital, o trabalhador também é engendrado no projeto de totalização do capital. Para Marx (2007, p. 240, grifos do autor) essa é a tarefa da alienação: na relação de proximidade entre o capital e o trabalho este "necessariamente se empobrece porque o poder criativo de seu trabalho estabelece-se como o poder do capital como um poder alienado, confrontando-o. [...] A real produtividade de seu trabalho, seu trabalho em geral, vem confrontar o trabalhador como uma força alienada. $O$ capital se realiza através da apropriação do trabalho alienado". 


\section{ELEMENTOS FUNDAMENTAIS DA ÉTICA DA LIBERTAÇÃO PARA A PRODUÇÃO DO BLOCO DE LUTAS DOS OPRIMIDOS \\ Guilherme Dornelas Camara}

A alienação, no processo de produção do capital, é vista por Dussel (2012, p. 332) como “o mal originário, a perversidade ética por excelência da realidade capitalista e por ele de sua moral (da moral burguesa introjetada no trabalhador, que aceita o capital como um dado natural) e de onde a ganância é um direito próprio do capitalista, pela propriedade dos bens que seu trabalho originário produziu". É interessante notar que, na Ética da Libertação, a relação de proximidade entre o trabalhador e o capitalista termina no momento da venda da força de trabalho. A venda da energia criadora, a alienação do trabalhador não é uma relação cara-acara entre o capitalista e o trabalhador, mas uma relação que ocorre entre as classes e entre as populações, de modo que a perversidade ética do sistema - denunciada por Dussel - está calcada não na alienação e no empobrecimento individual, mas na inclusão de grandes contingentes humanos na Totalidade do sistema capitalista como mera oferta de força de trabalho. Também por isso, não há saída individual da Totalidade.

É necessário compreender que as próprias contradições do sistema (e aqui remeto às notas de Marx sobre o empobrecimento e a superpopulação) impedem que todos estejam incluídos na Totalidade do sistema de um modo objetivamente concreto. Existe, para esses que não

atingem os postos de trabalho oferecidos pelo capital, apenas a oportunidade de viverem às margens do sistema, como Marx (2007) afirmava, obtendo o necessário para as suas vidas apenas porque lhes são jogadas esmolas da riqueza produzida.

Mas o trabalho não é sempre trabalho como capital. Enquanto trabalho vivo, potência criadora, o trabalho não-é capital; é sua Exterioridade. A partir de seu ser, o capital “descende à população para 'apreendê-la' em seu fundamento. De fato, na essência do capital está a produção de mais-valia. Como mais-valia absoluta, como massa de maisvalia, requer mais trabalhadores - aumenta a população" (DUSSEL, 2012, p. 343). No entanto, o desenvolvimento da maquinaria e a organização do processo de trabalho, diminui-se o tempo necessário e diminui-se a população subsumida como assalariada. Essa superpopulação, o pobre, o pauper, como Marx o chama é agora conceptualizado em sua relação de Exterioridade ao capital.

O horizonte ontológico da classe trabalhadora - mesmo que nãoassalariada, pobre, excluída - estabelece o desde-onde fazer a crítica à Totalidade do sistema capitalista, pois ao tomar o capital como 


\section{ELEMENTOS FUNDAMENTAIS DA ÉTICA DA LIBERTAÇÃO PARA A PRODUÇÃO DO BLOCO DE LUTAS DOS OPRIMIDOS \\ Guilherme Dornelas Camara}

fundamento para a realidade do trabalho nas sociedades capitalistas contemporâneas, o trabalho é uma determinação do capital e o trabalho vivo é alienado a este. Dussel (2012, p. 350) estabelece uma relação de proximidade, um cara-a-cara entre o capitalista e o trabalhador, na qual

a imediata corporalidade do trabalhador [...] se enfrenta com o rosto do capitalista, primeiro em abstrato (desde um ponto de vista econômico), depois em concreto (em uma hermenêutica existencial), mas ao mesmo tempo como duas classes, duas raças, dois povos. A esse homem, que violentamente coagido por condições objetivas que dissolveram as suas relações de apropriação com a terra, com os instrumentos e com os outros homens, presente em seu próprio corpo, frente ao capitalista, só resta, para não morrer de fome, vender-se a si mesmo, vender a sua capacidade de trabalho por um certo tempo.

Surgem, nesse horizonte a Utopia e a Libertação como oposição ao imperativo socialmente compartilhado de produzir valor-de-troca. Em Dussel (2012, p. 359), a utopia está presente como um lugar vislumbrado pelo trabalhador em sua Exterioridade ao capital. Essa utopia tem como pressuposto a sua libertação. Desde esse ponto de partida, que também é um ponto de chegada almejado,

a utopia é um 'para-além do horizonte ontológico, do ser do capital. A totalidade do capital é superada por um âmbito que transcendo o seu fundamento. Se a ontologia pensa o ser, a crítica do ser se efetua desde um [...] outro mundo que se aspira, espera, propõe e imagina como alternativa ao presente, injusto, perverso. A utopia futura é, assim, polo afetivo, tendencial que mobiliza a ação. O oprimido, alienado, subsumido no capital, tem asism um projeto de libertação que cria o fundamento para uma práxis revolucionária de libertação. Este homem, que hoje é oprimido, mas que hoje espera uma nova sociedade, e por ela luta, já se transforma, desde o presente em um 'homem novo'. 


\section{ELEMENTOS FUNDAMENTAIS DA ÉTICA DA LIBERTAÇÃO PARA A PRODUÇÃO DO BLOCO DE LUTAS DOS OPRIMIDOS \\ Guilherme Dornelas Camara}

Na Ética da Libertação, Dussel (2012, p. 372) situa a utopia e a libertação nas especificidades das nações periféricas. Referenciando Ruy Mauro Marini, o autor sublinha que "a distância e a pouca densidade do capital periférico o impedirão de concorrer com o capital central [...]. De fato, a essência última da debilidade do capital periférico consiste em que o processo de valorização útil é muito menor do que no Centro". Por isso, o recurso à extração de uma taxa mais-valor mais elevada com a superexploração da força-de-trabalho nos países periféricos. De acordo com Marini (2005), a superexploração se realiza com a articulação do aumento da intensidade do trabalho, do prolongamento da jornada e da expropriação de parte do trabalho necessário ao trabalhador para repor sua força de trabalho.

Frente a esse contexto, a utopia se realiza na analética, ou anadialética, isto é, na indicação de que o fato real humano é que todo homem, grupo ou povo se situa mais-além do horizonte da Totalidade vigente. A ana-dialética expressa "a negação da negação da Totalidade [que] só pode partir da afirmação da exterioridade analética ou da capacidade de transcendentalidade que o homem sempre tem por ser homem". Para a realização da libertação, a utopia se apresenta como a

formulação de uma teoria crítica radical, como organização das mediações políticas que efetivarão na história a nova ordem alternativa (DUSSEL, 2012, p. 346).

Para Dussel, os Grundrisse apresentam o desenvolvimento de categorias fundantes para uma Teoria da Libertação, mas não trazem muitos avanços para a análise das condições de vida da população enquanto Exterioridade na Periferia da Totalidade do sistema capitalista. A Teoria Marxista da Dependência, por sua vez, estabelece os termos essenciais para a compreensão das particularidades que a Totalidade apresenta na América Latina. Aqui o pobre é o indivíduo e o povo é a categoria que expressa a pobreza enquanto a realidade das massas (DUSSEL, 2012). “A partir da impossibilidade de que um país periférico subdesenvolvido chegue a ser central no capitalismo, as contradições do capitalismo se vivem na periferia como crise permanente e exploração crescente. Sendo as classes oprimidas da Periferia as que sofrem esta espoliação de modo necessário, são elas, igualmente, as que se transformam no sujeito revolucionário por excelência da história universal" (DUSSEL, 2012, p. 383). 


\section{ELEMENTOS FUNDAMENTAIS DA ÉTICA DA LIBERTAÇÃO PARA A PRODUÇÃO DO BLOCO DE LUTAS DOS OPRIMIDOS \\ Guilherme Dornelas Camara}

Cabe questionar, então, o que é o povo. Dusssel afirma que o povo não é um conglomerado amorfo, que melhor se definiria como massa, nem o estado dominante de determinada época. O povo, também, não deve ser confundido com 'classe', pois "a 'classe' desaparece com a totalidade que a determina”. Em um sentido estrito, “'povo' é um bloco social da sociedade civil, anti-hegemônico enquanto oprimido e explorado nas épocas finais de um sistema, de um modo de apropriação e produção, quando a estrutura não resiste ao impulso criador das forças produtivas e deve reprimir o surgimento de um novo sistema" (DUSSEL. 2012, p. 384-5).

Dussel chama a atenção de que o bloco social que constitui o povo não é Exterioridade apenas como classe, pois outros grupos sociais que guardam exterioridade também à nação o constituem. A importância política do conceito de 'povo' é revolucionária, para Dussel, pois o povo é sujeito histórico que atravessa os diversos modos de apropriação de uma formação histórica "com as memórias de suas gestas, com cultura própria, com continuidade no tempo [...]. O povo é o coletivo histórico de pobre nos momentos limites da aniquilação de um sistema e de passagem a outro".

Essa passagem, mirando para a utopia, está calcada na transcendência absoluta do povo, que é Outro, como ponto-de-partida. Nesse processo, a ana-dialética é o método que almeja realização de um novo sistema, mais-além da opressão, da dominação e da espoliação. $\mathrm{O}$ método ana-dialético apresentado pela Ética da Libertação possui três momentos: (1) o momento afirmativo da conscientização ética e crítica que é ouvir a interpelação do Outro desde sua corporalidade sofredora tem como questão os dominados e excluídos, para que tenham consciência concreta, histórica e existencial de sua opressão e de seu sofrimento. (2) o segundo momento é o negativo - e só pode ser vivido por aqueles que têm alguma 'experiência' de 'nós', com os dominados ou excluídos, que pensem reflexivamente sobre a miséria do Outro. Esse momento requer o reconhecimento de que há uma economia política da Totalidade e uma economia política do Outro, que é uma política da subversão e da negação da negatividade da exclusão e opressão dos pobres, das vítimas. Esse momento dá vida a uma nova consciência, que é cientificamente informada, resultando no Consenso dos Oprimidos. (3) O terceiro momento é de conscientização prática, histórica e existencial do povo, é o momento de organização, quando o consenso anti-hegemônico é expressado nas lutas e na construção de alternativas (DUSSEL, 2004). 


\section{ELEMENTOS FUNDAMENTAIS DA ÉTICA DA LIBERTAÇÃO PARA A PRODUÇÃO DO BLOCO DE LUTAS DOS OPRIMIDOS \\ Guilherme Dornelas Camara}

Nesse sentido, a Ética da Libertação aporta uma contribuição importante para a formação de um Bloco de Lutas dos Oprimidos, pois elabora análises e conceitos que informam a conscientização do povo e a constituição das lutas anti-hegemônicas. A Ética da Libertação oferece elementos para a construção de alternativas não só para o pobre, mas para todo o povo em suas diversas manifestações como vítimas, como Exterioridade absoluta que enfrenta a Totalidade do sistema capitalista.

\section{Considerações Finais}

A Ética da Libertação não se dá a qualquer situação hipotética de uma sociedade pretérita ou futura, pois só pode ser estabelecida a partir da realidade de exploração, opressão e expropriação que caracterizam a atualidade da tessitura do conjunto de relações socioeconômicas que determinam o sistema capitalista, em especial nos países que compõem a Periferia do sistema-mundo (DUSSEL, 2004). A Ética da Libertação não apenas faz tal afirmação, mas nega a exploração, a moral capitalista, a abordagem utilitarista que individualiza os sujeitos e os apresenta como exterior à natureza que transformam. A universalidade do princípio éticomaterial da Filosofia da Libertação reside justamente na vida concreta das pessoas, dos pobres, do povo e no devir do concreto-pensado, concreto subjetivado, que mira para a reprodução e manutenção da vida humana com a superação do modo de produção vigente.

A categoria 'povo', situada desde a concretude da economia política capitalista e mirando para a utopia e a libertação, faz enxergar a cultura de resistência e a organização própria dos pobres. No entanto, Dussel (2012, p. 387) destaca que "se tornam necessárias uma organização política e a formulação de uma teoria verdadeiramente revolucionária [...] e, para tanto, deve contribuir a filosofia latino-americana, sob pena de esterilizarse, mostrar-se inútil e inautêntica".

Assim, a Ética da Libertação informa-se juntamente com o povo, vislumbrando a realização de um sistema em que "o produto 'social' a partir do seu fundamento e o local de trabalho seria um espaço humano do frente a frente, da proximidade, da liberdade real, da igualdade justa, da fraternidade concreta. A partir desse ponto de vista se pode entender que a 'proximidade' originária de uma organização comunitária do trabalho se situa na Exterioridade de um sistema no qual o ser social é 


\section{ELEMENTOS FUNDAMENTAIS DA ÉTICA DA LIBERTAÇÃO PARA A PRODUÇÃO DO BLOCO DE LUTAS DOS OPRIMIDOS \\ Guilherme Dornelas Camara}

outorgado pelo 'mundo' das mercadorias (alheio, alienado)." (DUSSEL, 2012, p. 90-1).

Em exterioridade à Totalidade do sistema capitalista, as evidências mostram que por todo o mundo, e especialmente na América Latina, o povo inaugura o momento de transformação, orientado para a libertação. A inauguração desse mais-além da Totalidade capitalista interpela todos que estão em relação de proximidade com o Povo.

\section{Referências}

ALEXANDER, Larry; MOORE, Michael. Deontological Ethics. The Stanford Encyclopedia of Philosophy, winter, 2012. Disponível em: $<<$ http:/ / plato.stanford.edu/archives/win2012/entries/ethicsdeontological/>. Acesso em 10 set. 2013.

DUSSEL, Enrique. Introducción a la filosofia de la liberación. Bogotá: Nueva América, 1995.

Ética de la Liberación (Hacia el "punto de partida" como ejercicio de la "razón" ética originaria). In: APEL, Karl-Otto; DUSSEL, Enrique. Ética del discurso y ética de la liberación. Madrid: Trotta, 2004. p. 269-290.

Ética da libertação: na idade da globalização e da exclusão. Petrópolis: Vozes, 2002.

A Produção Teórica de Marx: um comentário aos Grundrisse. 1 ed. São Paulo: Expressão Popular, 2012.

FERRATER MORA, José. Diccionario de Filosofía Abreviado. 1 ed. Buenos Aires: Debolsillo, 2007.

FREIRE, Paulo. Conscientização: teoria e prática da libertação. São Paulo: Cortez \& Moraes, 1970.

KANT, Immanuel. Fundamentação da Metafísica dos Costumes e Outros Escritos. São Paulo: Martins Claret, 2005.

LÉVINAS, Emmanuel. Entre Nós: Ensaios sobre a alteridade. 2 ed. Petrópolis: Vozes, 2005.

. Totalidade e Infinito. Lisboa: Edições 70, 2000. 
MARINI, Ruy Mauro. Dialética da Dependência. In: TRASPADINI, Roberta; STEDILE, João Pedro (orgs.). Ruy Mauro Marini: vida e obra. São Paulo: Expressão Popular, 2005. p. 71-113.

MARX, Karl. Elementos Fundamentales para la Crítica de la Economía Política (Grundrisse). 1857-1858. 20 ed. Ciudad de México: Siglo XXI, 2007.

O Capital(Crítica da Economia Política). Livro 1. O Processo de Produção Capitalista. Rio de Janeiro: Ed. Civilização Brasile

Submetido em: 27/10/2016

Aprovado em: 11/01/2017 